\title{
Exploration of an experimental curriculum system for applied Financial Management

\author{
Lingyi Kong
}

Wenjing College, Yantai University, Yantai 264005, China

kongly01@163.com

Keywords: Occupational competency; Financial Management; Experimental curriculum system

\begin{abstract}
Oriented towards occupational competency, independent institutes cultivate Financial Management talents. However, currently, the experimental curriculum system for Financial Management is not complete. There are a series of problems existing in attention to experimental teaching, experimental teaching methods, experimental teaching process, lab software and hardware, experiment faculty, etc. It is necessary for independent institutes to build and complete the experimental curriculum system for Financial Management, improve students’ professional skills and bring up applied financial management talents serving social and economic development.
\end{abstract}

\section{Introduction}

David McClelland, an American scholar, first put forward the concept of "occupational competency," and studied behavioral characteristics and individual traits of competent personnel [1-2]. Based on a questionnaire survey of 120 enterprises and a PEI behavior interview, this paper finds out that the current Financial Management talents brought up in colleges and universities can hardly meet market demands. Many employers say that graduates of Financial Management have a consolidate theoretical knowledge system but poor practical abilities, especially professional skills, which make them incompetent to positions related to financial management [3]. It is hard for employers to judge whether graduates have the required professional skills according to academic degree and professional performance. This also reflects a problem, that is, universities and colleges have failed to bring up financial management talents oriented towards occupational competency meeting requirements of economic demands [4].

Independent institutes should be different from universities and colleges in terms of talent development goals. The former should attach great importance to bringing up applied talents with professional skills. Therefore, Financial Management in independent institutes should be positioned to serve regional economic construction, emphasize on coordinated development of knowledge, abilities and qualities, and bring up highly-qualified applied talents. These applied talents should be competent to financial management, financial analysis, financial consulting, securities investment and accounting in industrial and commercial companies, financial companies, securities companies, insurance companies, banks, government departments and social agencies. Besides, they should be equipped with solid theoretical knowledge, practical skills, innovational spirit and ability, and development potential.

Content of the experimental curriculum system for Financial Management of independent institutes 
Content of the experimental curriculum system for Financial Management of independent institutes. Currently, the experimental curriculum system for Financial Management is made up of three parts, namely basic experiment courses, specialized course experiments and comprehensive experiments. The experimental courses should have a clear objective and be combined with professional skills. Basic experimental courses include Basic Accounting Experiments and Financial Management Experiments, and develop financial accounting and project management of students. Specialized experimental courses include Intermediate Financial Accounting Experiments, which teaches students cope with complex accounting tasks; Tax Financial Experiments, which helps students develop the tax declaration ability; Management Accounting Experiments, which develops students' ability to raise funds and employ the accounting information to manage companies; Cost Accounting Experiments, which endow students with the ability of cost accounting; Financial Analysis Experiments, which develops students' ability to analyze financial statements and financial budgets; Auditing Experiments, which fosters students' ability of accounting supervision. Comprehensive experiments include Accounting Manual Simulation Experiments, which develops students' ability to handle accounting tasks according to different links of different positions; Accounting Computerization Experiments, which helps students learn to use UFIDA software and relies on Internet to realize computerization of accounting tasks; ERP Sand-table Simulation Experiments, which develop students' ability of project decision-making, project management and capital allocation.

Necessity to closely combine theoretical courses, basic experimental courses and specialized experimental courses for Financial Management. Basic course experiments, specialized course experiments and comprehensive experiments are systematical requirements of the experiment curriculum system for Financial Management. Basic course experiments are mostly operational and empirical experiments. While learning theoretical courses, students should also do some relevant experiments so that they can combine theories with practices and learn how to put theories into practices. Specialized course experiments are based on learning basic curriculum experiments and specialized theoretical courses. They are further learning and training of professional skills of Financial Management majors. Besides, they are partly operational and empirical, and partly design-oriented and analytical. Comprehensive financial management experiments are comprehensive, analytical and design-oriented. Combining applied accounting, financial management, financial analysis and tax laws, they aims at enhancing students' specialized skills and general abilities.

\section{Countermeasures for improvement of the experiment curriculum system for Financial Management of independent institutes}

Pay more attention to the experiment curriculum system for Financial Management. In order to bring up applied financial management talents, independent institutes have set up a series of experiment courses, including basic accounting experiments, financial management experiments and financial analysis experiments. However, independent institutes are paying less attention to experiment courses than to theoretical courses. The main reason for the problem is that the teacher-student ratio is too low. Usually, a teacher needs to give experiment lessons to more than one hundred students. Under the condition, the teacher can only give a brief introduction of experiment content and steps. It is impossible for him to give timely guidance to every student. This greatly reduces the teaching effect. 
Properly and scientifically combine theoretical courses and experimental courses. Theoretical courses and experiment courses for Financial Management majors are often separated, which also cut the connection between theoretical knowledge and practical operation. Financial Management in independent institutes should be positioned to develop applied financial management talents. The theoretical courses should not focus on knowledge difficulty but on combination with practices. The combination of theoretical and experiment courses is to synchronize the practice content involved in the theoretical interpretation process so as to help students learn how to apply their theoretical knowledge to practices. Experiment courses and theoretical courses involved in the basic experiment course link and the specialized experiment curriculum should be coordinated in terms of their time arrangement. For example, while teaching Basic Accounting, students should integrate theoretical teaching and practical operation based on Basic Accounting Experiments. In this way, students can master theoretical knowledge and operational skills in time. To apply classroom knowledge to practices can enhance students' understanding of theoretical knowledge, and help them master practical accounting skills, including how to fill up original vouchers, compile accounting vouchers and categorized accounts summary, open up accounts, put accounting records down, check and settle accounts. In this way, the teaching effect can be greatly improved.

Enhance lab construction for Financial Management. Lab construction is an important guarantee for the specialized curriculum teaching for Financial Management. The experiment teaching for Financial Management calls for a specialized lab equipped with UFIDA ERP financial management software, tax declaration software, auditing software and financial decision-making software, etc. Besides, the experiment environment should not be a simply adding of machine rooms and software, but also include simulation of practical financial management procedures in companies. By doing so, students can accommodate to real financial management activities, professional procedures and treatment in the future. The simulation environment should be set up with the business administration section, the tax administration section and the bank section so that students can do experiments according to the financial management procedures and expose themselves to the future work training and environment. Moreover, independent institutes should attach great importance to the construction the manual account simulation lab, the financial management computerization lab, the ERP sand-table lab and the financial simulation lab.

Intensify reform of experiment curriculum teaching methods. The experiment content should reduce the percentage of demonstration and empirical experiments but increase the percentage of applied, design-oriented and comprehensive experiments. The experiment courses can organize group learning, in which students can give full play to their initiative and develop awareness of teamwork. Experiment learning should not be confined to labs. After class or on weekends, learning groups can discuss with each other and refer to relevant materials to finish experiment assignments. During the group learning process, students can not only enhance their professional skills, but also hone their teamwork ability, learning and development ability, logic analysis ability, etc.

Strengthen the "instructor-engineering” faculty construction and improve young teachers' practical skills. Teachers are a guide to the whole experiment teaching process. Their qualities directly decide the overall quality of experimental teaching. In the faculty structure of independent institutes, the percentage of middle-aged and young teachers is huge. Many postgraduates directly go to work in independent institutes after graduation. These young teachers lack professional teaching experiences. Due to lack of practical skills, they do not have a deep understanding of 
fund-raising, investment, capital operation, profit distribution, tax planning and other practical operations related to financial management. A correct way to solve the problem is to increase the percentage of the "instructor-engineer" faculty. On the one hand, independent institutes should provide opportunities for young teachers to take internships in companies to increase their practical skills; on the other hand, schools should build connections with companies, and invite personnel with rich practical experiences to give lessons to teachers. By doing so, independent institutes can not only improve the practical curriculum teaching effect, but also help young teachers enrich their financial management practices and practical abilities.

Formulate a management system for practice teaching and refine management standards. Strengthen experiment examination process management: Currently, independent institutes give too much attention to theoretical course examination, but ignore experiment course examination. Students take experiment lessons, come up with experiment results and submit experiment reports. That's all. Due to the examination system, experiment course examination focus just on results not on the process. As a result, some students might have not yet mastered the required skills, but still pass the examination. In this way, the experiment teaching effect is poor. Independent institutes should comprehensively exam students' standardability of experiment operation, familiarity, and ability to apply theoretical knowledge and other links related to professional skills. Whether students pass the examination or not is decided by whether they have master the required skills.

Build an efficient experiment examination system. In order to achieve the expected results and improve students' professional skills, independent institutes should emphasize on the experiment examination process featuring "process management" The examination content and percentage for experiment courses can be designed in the following way: 15\% for attendance; $15 \%$ for course performance, $60 \%$ for experiment project skills and $10 \%$ for experiment report. The score for attendance is worked out by dividing the total attendance times with the due attendance times and multiply the result with 100; course performance should be judged by the supervisor according to the nature of the experiment course and students' question-answering, and group discussion situations; experiment project skills are scored according to students' operation accuracy, and they are the major part of the whole examination, aiming at endowing students with practical skills; experiment reports are a last experiment link, in which students can write about their question discovery, question analysis and experiment experiences. By examining students' experiment reports, teachers can learn how to improve the experiment links and the teaching effect.

\section{Conclusions}

To bring up applied Financial Management talents oriented towards occupational competency and serving social and economic development is a development trend for Financial Management talent training of independent institutes. This paper puts forward a framework for the construction of an experiment curriculum system for applied Financial Management, and offers strategies to further improve the system in independent institutes. Only through constant exploration of the experiment curriculum system for Financial Management can independent institutes efficiently improve professional skills of Financial Management majors and make them competent to future financial management positions.

\section{Acknowledgements}


This work was supported by the Teaching Reform and Research Project of Wenjing College, Yantai University（2014JYB016）

\section{References}

[1] Ma Y H. Financial management teaching reform in line with innovational capability cultivation, Friends of Accounting. 6 (2009) 66-68.

[2] Rong H X \& Chi Y Q. Financial management professional experiment system building, the Border Economy and Culture. 9 (2013) 14-15.

[3]Cui B. Building and optimization of financial management undergraduate professional lab teaching system in universities and colleges, Modern Enterprise Education. 2 (2014) 89-91.

[4]Yang F. Optimization of the applied financial management professional lab teaching system, Commercial Accounting. 24 (2013) 126-128. 